\title{
Pressurized hot water extraction of hydrosable tannins from Phyllanthus tenellus Roxb.
}

\author{
Noor Hidayah Mohd Jusoh ${ }^{1}$, Atiqah Subki ${ }^{1}$, Swee Keong Yeap ${ }^{2}$, Ken Choy Yap ${ }^{3}$ and Indu Bala Jaganath ${ }^{1^{*}}$ (I)
}

\begin{abstract}
Background: Safety, environmental and economic setbacks are driving industries to find greener approaches to extract bioactive compounds from natural resources. Pressurized hot water extraction (PHWE) is among the solvent free and efficient methods for extracting bioactive compounds.
\end{abstract}

Experimental: In this study, the suitability of PHWE for extracting bioactive compounds such as phenolics, hydrolysable tannins and flavonoids from Phyllanthus tenellus was investigated by UPLC-qTOF-MS.

Results: Solvent properties of water are significantly increased through imposing temperature at $121^{\circ} \mathrm{C}$ and pressure at 15 p.s.i. Pressurized hot water extraction obtained 991 -folds higher hydrolysable tannins than methanol extraction.

Conclusion: The extraction yields of hydrolysable tannins with PHWE was almost double of absolute methanol extraction.

Keywords: Phyllanthus, Phytochemicals, Pressurized hot water extraction

\section{Introduction}

Phyllanthus tenellus Roxb., an herbaceous plant belonging to the family of Euphorbiaceae, is closely related to the commonly known Phyllanthus niruri. Similar to P. niruri, it is also known for its health benefiting properties. This plant is used to treat urolithiasis, inflammatory bowel disease, diabetes and hepatitis B [1]. Phyllanthus sp. are known to contain high levels of hydrolysable tannins which have been frequently associated with its antiviral activity [2,3]. Besides, many therapeutic effects have been reported such as anti-oxidant, anti-inflammatory and analgesic effect. Currently there is mounting interest in screening plant sources for anti-viral agents. The genus Phyllanthus is also a rich source of phenolics and

\footnotetext{
*Correspondence: indu@mardi.gov.my

${ }^{1}$ Metabolomics Laboratory, Biotechnology Centre, Malaysian Agriculture Research and Development Institute (MARDI), Serdang, Selangor, Malaysia

Full list of author information is available at the end of the article
}

also contains flavonoids, alkaloids, terpenoids and sterols [4-6].

One of the most important step which determines the final outcome of the quality of the herb is the extraction process. Various organic solvents with different polarities such as methanol, hexane, chloroform, acetonitrile, benzene and ethyl alcohol has been used over the years to optimize extraction of bioactive compounds. However, these solvents are not only toxic both to humans and the environment; they are also expensive especially when carried out at an industrial scale. In more recent studies, extraction has advanced to using new and simpler techniques such as microwave-assisted extraction, supercritical fluid extraction, pressurized liquid extraction and ultrasound-assisted extraction $[7,8]$.

One of the cleanest and green technologies is just to use water as the solvent. To enhance the solvent properties of water, water in a pressurized hot water extraction (PHWE) can readily alter its physico-chemical properties such as 
its self-ionization, dielectric constant, viscosity, diffusivity, density and surface tension [9]. PHWE is reported to also exhibit shorter extraction time, lower costs of the extracting agent, and an environmentally compatible technique.

In this study, a system of applying pressure to water at high temperature in an autoclave was used to extract bioactive compounds in P. tenellus. We hypothesized that an autoclave treatment could facilitate an efficient extraction of bioactive compounds from $P$. tenellus. This extraction method was compared to water and methanol extraction. The bioactive compounds in the different treatments were profiled using ultra-high pressure liquid chromatography coupled to a quadrupole tandem time of flight (UHPLC-QTOF High Resolution) mass spectrometer system. The results suggest that pressurized hot water extraction can successfully be used for the extraction of P. tenellus bioactive compounds as the extraction yields of hydrolysable tannins with PHWE was almost double of absolute methanol extraction.

\section{Experimental}

\section{Chemicals and standards}

The reference standards (gallic acid and ellagic acid) were both purchased from Sigma Chemicals (USA) at purity of $98 \%$. Solvent and mobile phase (acetonitrile, methanol and formic acid) used for LCMS-MS were HPLC grade, which obtained from MERCK, Germany. Ultra-pure water (Aquamax-ultra) was used to prepare all samples and buffer. Pure methanol (100\% purity) was used in the preparation of the methanol extracts also obtained from MERCK, Germany.

\section{Collection and preparation of plant material}

Fresh leaves of P. tenellus (MD10525) were collected from the green house at Malaysian Agricultural Research and Development Institute (MARDI), Malaysia where they were cultivated under semi-controlled environmental conditions. Freshly harvested plants were washed and dried in room temperature. Air-dried leaves were then kept in freezer at temperature of $-80^{\circ} \mathrm{C}$.

\section{Water extraction at room temperature}

About $1 \mathrm{~g}$ of chopped air dried leaves of $P$. tenellus were homogenized and thoroughly mixed with $20 \mathrm{~mL}$ of double deionized water and then centrifuged at $8900 \mathrm{rpm}$ in $4{ }^{\circ} \mathrm{C}$ for $5 \mathrm{~min}$. The supernatant was collected after two rounds of extraction and freeze dried (Labconco, vacuum $0.120 \mathrm{mBAr}$, temperature $-51^{\circ} \mathrm{C}$ ). The percentage yield was calculated using the Eq. 1 below;

$$
\operatorname{Yield}(\mathrm{Y})=\frac{\mathrm{Wf}}{\mathrm{Wi}} \times 100
$$

where $\mathrm{W}_{\mathrm{f}}$ is the final weight of crude extract $(\mathrm{g}), \mathrm{W}_{\mathrm{i}}$ is initial weight of extract (g). Samples were re-dissolved into final concentration of $20 \mathrm{mg} / \mathrm{mL}$ with $30 \%$ methanol and filtered through a syringe filter $(0.22 \mu \mathrm{m})$ before being subjected for UPLC-QTOFF MS system.

\section{Methanol extraction}

About $1 \mathrm{~g}$ of chopped air dried leaves of $P$. tenellus were weighed and thoroughly mixed with $20 \mathrm{~mL}$ of methanol and then centrifuged at $8900 \mathrm{rpm}$ in $4{ }^{\circ} \mathrm{C}$ for $5 \mathrm{~min}$. The supernatant was filtered with Whitman No 1 filter paper and repeated again with adding another $20 \mathrm{~mL}$ of methanol. The filtrate was then dried with a vacuum concentrator (Eppendorf concentrator 5301) into powder form. The percentage yield was calculated using Eq. 1 as mentioned before. Samples were re-dissolved into final concentration of $20 \mathrm{mg} / \mathrm{mL}$ with $30 \%$ methanol and filtered through a syringe filter $(0.22 \mu \mathrm{m})$ before being subjected for UPLC-QTOFF MS analysis.

\section{Water extraction at elevated temperatures and pressure}

About $1 \mathrm{~g}$ of air dried $P$. tenellus leaves were homogenized and thoroughly mixed with $20 \mathrm{~mL}$ of double deionize water and then autoclaved for $20 \mathrm{~min}$, at a temperature of $121{ }^{\circ} \mathrm{C}$ and a pressure of $100 \mathrm{kPa}(15 \mathrm{psi}$ ) (Hirayama hiclave, HVE-50). The supernatant was collected and freeze dried (Labconco, vacuum $0.120 \mathrm{mBAr}$, temperature $-51{ }^{\circ} \mathrm{C}$ ). The percentage yield was calculated using the Eq. 1. Samples were re-dissolved into a final concentration of $20 \mathrm{mg} / \mathrm{mL}$ with $30 \%$ methanol and filtered through a syringe filter $(0.22 \mu \mathrm{m})$ before being injected directly into an ultra-high pressure liquid chromatography coupled to a quadrupole tandem time of flight (UHPLC-QTOF High Resolution) mass spectrometer system.

\section{Phytochemical detection and identification of $P$. tenellus leaves}

Phytochemical analysis of $P$. tenellus was performed using a Eksigent ultraLC $100 \mathrm{UHPLC}^{\mathrm{TM}}$ system (Sciex, Framingham, MA, USA), which was equipped with dual pump delivery system coupled to a SCIEX 5600+ QTOF mass spectrometer (Sciex, Framingham, MA, USA) equipped with an electrospray ionization (ESI) interface. Chromatographic separations were performed on a Thermo Hypersil Gold $150 \mathrm{~mm} \times 4.6 \mathrm{~mm}$ analytical column. The column was maintained at $40{ }^{\circ} \mathrm{C}$ and eluted with a step gradient from $95 \%$ acetonitrile $(0.05 \%$ $(\mathrm{v} / \mathrm{v})$ formic acid) $-5 \%$ aqueous formic acid $(0.05 \%(\mathrm{v} / \mathrm{v})$ formic acid) to $5 \%$ aqueous formic acid $(0.05 \%(\mathrm{v} / \mathrm{v})$ formic acid- $95 \%$ acetonitrile $(0.05 \%(\mathrm{v} / \mathrm{v})$ formic acid) over $67 \mathrm{~min}$ at a flow rate of $1.0 \mathrm{~mL} / \mathrm{min}$. About $20 \mu \mathrm{L}$ injection of this sample was made onto the column. 
The system was calibrated and optimised using Sciex internal negative ESI tuning mix solutions, which was injected for every three injections between sample runs. The mass spectrometer was operated in negative ion (NI) mode with general unknown screening methodology. An unknown screening mode using TOF MS scan experiment at $100-1200 \mathrm{~m} / \mathrm{z}$ with information dependant acquisition ion detector array (IDA) of product ion scan (MS/MS) experiment at $50-1200 \mathrm{~m} / \mathrm{z}$ for fragment ion spectra generation, both experiment performed simultaneously. The pseudo-MS ${ }^{3}$ experiment in the NS/precursor ion MS/MS mode, when performed on a triple quadrupole instrument equipped with an ESI source, involves three steps as described by Chen et al. [10]. 5 maximum number of ions per cycle were monitored, to obtain all relevant ions at proper and acceptable intensity, to be fragmented. The desolvation temperature was set to $500{ }^{\circ} \mathrm{C}$ with ionisation and desolvation gas set at 40 psi each. The ion spray voltage was set at $4500 \mathrm{kV}$ with de-clustering potential set at $80 \mathrm{eV}$.

The data was collected between 100 and $1200 \mathrm{~m} / \mathrm{z}$ with a low-level collision energy at $10 \mathrm{eV}$ for precursor ion information generation and a collision energy spread of $35 \mathrm{eV} \pm 15 \mathrm{eV}$ for fragment ion information. Dynamic background subtraction was employed continuously during sample run to reduce background ion interferences. Analyst TF 1.6 software was used for instrument control and data processing. PeakView 2.1 software was used for further data interpretation and fragment ion identifications.

\section{Calculation of relative quantification for the identified compounds}

The relative quantity each constituent detected were calculated as Eq. 2 below;

$$
\text { Relative quantification }(\mathrm{Rq})=\frac{\mathrm{TIC}}{\mathrm{TTIC}} \times 50
$$

where TIC is the total ion count for each compound, TTIC is the total of total ion count for the whole compounds identified in each run and 50 is the dilution factor of the reaction.

\section{Result and discussion}

\section{Total extraction yield using different solvents}

In this experiment, two different solvents were used, water and methanol with three different approaches. Both room temperature and pressurized hot water extract were recorded with significantly higher relative yield than methanol extract (Fig. 1). The PHWE extraction technique was postulated to improve extraction performance by aiding in the rupturing of the cells and release of phytochemicals. In addition, higher temperature increases

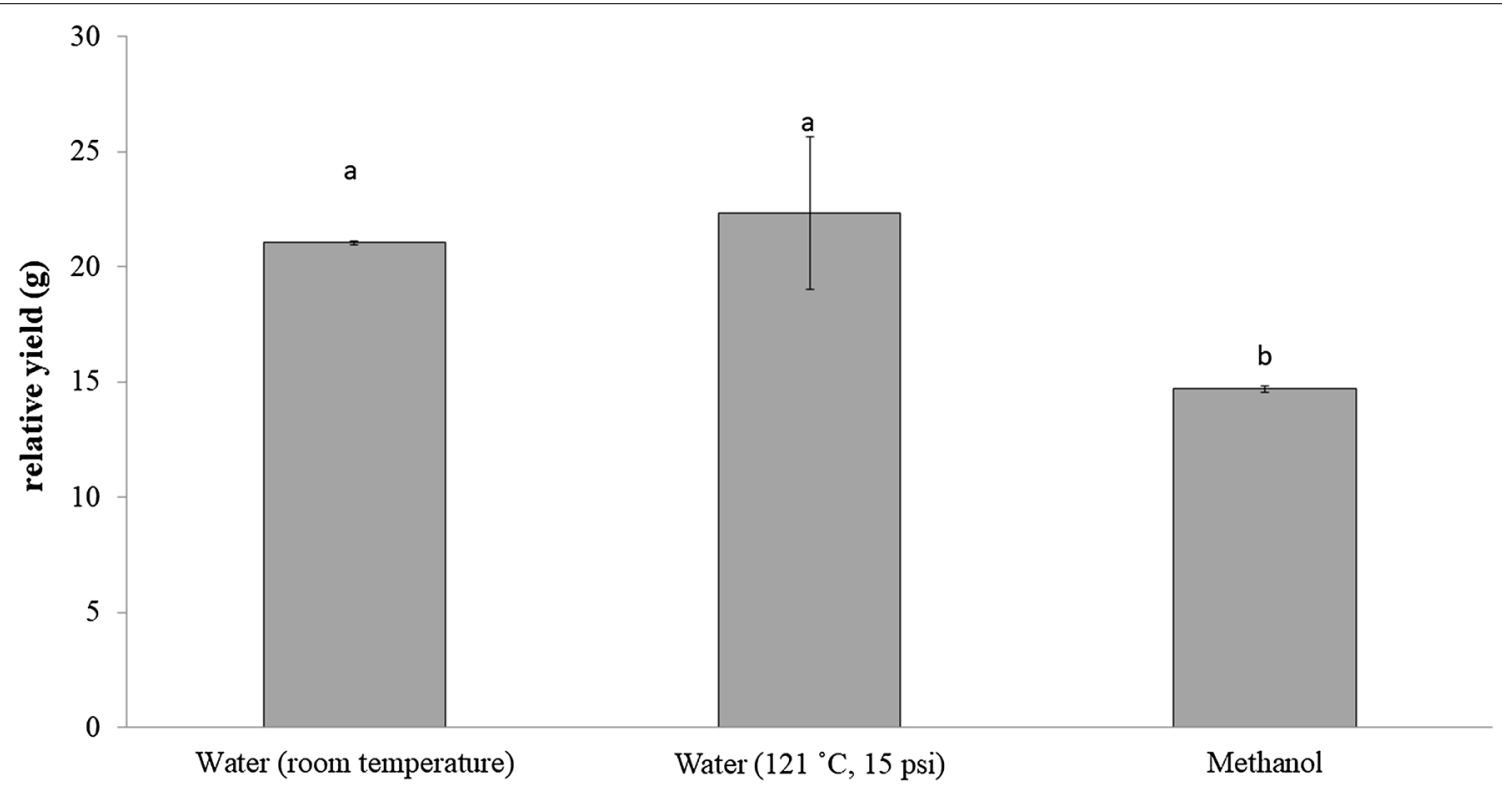

Extraction procedure

Fig. 1 Yield of extraction based on different extraction methods. The yields of different extraction procedures; water (room temperature), water $\left(121^{\circ} \mathrm{C}, 15 \mathrm{psi}\right)$ and methanol extract. The order of crude yield: (methanol $(14.7)<$ water (room temperature) $(21.05)<$ water $\left(121^{\circ} \mathrm{C}, 15 \mathrm{psi}\right)(22.35)$ extract. Triplicates of results were analyzed by one-way ANOVA with Tukey post hoc and presented as SEM. Different letters indicate significant differences between extract $(p<0.05)$ 
solubility and simultaneously reduces surface tension of solvents which in turn contributes to higher extraction rate [11]. Previously, the highest extraction yield was also observed in water extract of $P$. niruri Linn by $26.2 \pm 1.6$ [6] followed by methanol extract at $14.6 \pm 1.1$. The polarity index by Snyder [12] revealed that water and methanol have polarity index of 9.0 and 6.6 respectively making water a more polar solvent followed by methanol. Methanol as an extraction solvent is usually used for the extraction of semi-polar to non-polar compounds. Water has a dielectric constant of approximately 80 at room temperature. By increasing the pressure and temperature, the dielectric constant decreases and becomes similar to ethanol, indicating that water can be used to extract a wider range of polar and non-polar components [13-16]. This may justify the higher percentage yield when the PHWE was used compared to methanol extract.

\section{Phytochemical identification and relative quantification}

Screening and identification of phytochemicals were achieved by an untargeted UPLC-qTOF-MS at negative ionization mode. For metabolite identification, MS fragmentation patterns were used in conjugation with chemical libraries. Two characteristics wavelengths, i.e. $280 \mathrm{~nm}$ for detection of phenolic compounds such as hydrosable tannins and $360 \mathrm{~nm}$ for flavonoid [17] were used in this experiment.

A total of 28, 15, and 38 phytochemicals were identified in water (room temperature), PHWE and methanol extract, respectively as shown in Table 1 . Different solvents were able to extract different number and/or types of compounds. PHWE can extract from polar to least polar compound while methanol extract semi-polar to non-polar compound. There are four major group of compound that has been extracted, namely, phenolic acids, hydrosable tannins, condensed tannins and flavonoids.

\section{Phenolic acids}

The phenolic acids and flavonoids that were detected in the extracts are:

Quinic acid (tetrahydroxycyclohexane carboxylic acid) was found in all extracts and the relative quantitative in PHWE was found to be the highest followed by methanol and water (room temperature) extracts. Quinic acid is widely found in plant particularly in coffee bean. The identity of quinic acid with $\mathrm{m} / \mathrm{z} 191$, has the characteristic fragments of $m / z 111[\mathrm{M}-\mathrm{H}-80]^{-}$(loss of two water $\left(\mathrm{H}_{2} \mathrm{O}\right)$ molecules and carbon dioxide $\left(\mathrm{CO}_{2}\right), 93[\mathrm{M}-\mathrm{H}-$ $18]^{-}\left(\right.$loss of $\left.\mathrm{H}_{2} \mathrm{O}\right)$ and 87.

B-glucogallin is formed from esterification of gallic acid and B-D-glucose. Compound B-glucogallin $[\mathrm{M}-\mathrm{H}]^{-}$ion at $\mathrm{m} / \mathrm{z} 331$, and MS/MS fragment ions at $\mathrm{m} / \mathrm{z} 211$ [M-H-120] $]^{-}$. Formation of gallic acid with $\mathrm{m} / \mathrm{z}$ $169[\mathrm{M}-\mathrm{H}-162]^{-}$occurred from loss of glucoside and $\mathrm{m} / \mathrm{z} 125$ [M-H-44] $]^{-}$(loss of $\mathrm{CO}_{2}$ ). Relative quantification revealed that $\mathrm{B}$-glucogallin is again higher in PHWE extract than methanol extract.

Caffeic acid (3,4-dihydroxy cinnamic acid) with $\mathrm{m} / \mathrm{z}$ 179 and characteristic MS/MS fragment ion of 135 was found in PHWE and methanol extract. Recent studies emphasized the role of this compound as anticarcinogenic toward skin cancer. 2,5-dihydroxycinnamic acid with $\mathrm{m} / \mathrm{z} 179$ and characteristic MS/MS fragment ion of 158,140 and 135 on the other hand, was found in water (room temperature) and methanol only. Caffeoylmalic acid with $\mathrm{m} / \mathrm{z} 179$ and characteristics MS/MS fragment ions of 133,115 and 71 is the ester of caffeic acid was detected the highest in methanol followed by PHWE and water (room temperature) extract. Caffeic acid 3-glucoside with $\mathrm{m} / \mathrm{z} 341$ and characteristics MS/MS fragment ions of 179,135 and 133 has been found in water (room temperature), PHWE and methanol tentatively in an increasing order. It is actually a trans-caffeic acid that attached to a beta-D-glucopyranosyl residue at position 3 by glycosidic linkage. Compound 2-O-caffeoyl glucarate with $\mathrm{m} / \mathrm{z} 371$ and characteristics MS/MS fragment ions of 191, 147 and 85 was identified only in PHWE.

Chlorogenic acids (CGAs) are a type of phenolic compounds formed from the esterification of quinic acid and caffeic acid. Caffeoylquinic acids, coumaroylquinic acid and feruloyl quinic acid are three compounds classes under CGAs. CGAs are abundantly found in coffee bean. Chlorogenic acid (CA) was found in the water extract (room temperature) but not PHWE. This is in line with the nature of this compound, which is thermally unstable. In high temperature, CA will decompose into quinic acid and caffeic acid, which explains the higher presence of these two compounds in the PHWE.

Coumaric acid was found in PHWE only. It has $\mathrm{m} / \mathrm{z}$ of 163 and characteristics fragments of $\mathrm{m} / \mathrm{z} 119,117$ and 93. $o$-coumaroylquinic acid showed a $[\mathrm{M}-\mathrm{H}]^{-}$ion at $\mathrm{m} / \mathrm{z}$ 337, and MS/MS fragment ions at m/z 191 [M-H-146] (loss of gallic acid) can be found in PHWE. On the other hand, coumaroylquinic acid can be found only in water (room temperature) and methanol extract. Compound 4-O-beta-D-glucosyl-4-coumaric acid was identified in water (room temperature) extract only with $\mathrm{m} / \mathrm{z}$ of 325 and MS/MS fragment ions at m/z 179, 163 and 119.

Other compounds like 1-O-(2-acetpxybenzoyl)- $\beta$ D-glucopyranuronic acid was found in ascending concentration of water (room temperature), PHWE, and methanol. It has m/z 355 and MS/MS at 211, 169 and 151. Compound 2,4-Dihydroxy-6-(3-methylbutoxy)-3-(3methylbutyl) benzaldehyde was found only in PHWE extract. It has configuration of $\mathrm{m} / \mathrm{z}$ of 293 and MS/MS 
Table 1 Identification of chemical constituents in water $\left(121^{\circ} \mathrm{C}\right.$, $\left.15 \mathrm{psi}\right)$, water (room temperature) and methanol extract of $P$. tenellus leaves

\begin{tabular}{|c|c|c|c|c|c|c|}
\hline \multirow[t]{2}{*}{ No } & \multirow[t]{2}{*}{ Compound identity } & \multirow[t]{2}{*}{$\mathrm{m} / \mathbf{z}$} & \multirow[t]{2}{*}{ Compound classification } & \multicolumn{3}{|c|}{ Average relative quantification (\%) } \\
\hline & & & & PHWE & $\begin{array}{l}\text { Water (room } \\
\text { temperature) }\end{array}$ & Methanol extract \\
\hline 1 & Quinic acid & 191 & Phenolic acid & $0.147 \pm 0.050^{b}$ & $0.197 \pm 0.030^{b}$ & $0.068 \pm 0.009^{a}$ \\
\hline 2 & Caffeoylmalic acid & 295 & Phenolic acid & $0.029 \pm 0.008^{a}$ & $0.017 \pm 0.015^{\mathrm{a}}$ & $0.361 \pm 0.050^{b}$ \\
\hline 3 & Caffeic acid 3-glucoside & 341 & Phenolic acid & $0.055 \pm 0.040^{b}$ & $0.181 \pm 0.001^{c}$ & $0.007 \pm 0.004^{\mathrm{a}}$ \\
\hline 4 & $\begin{array}{l}\text { 1-O-(2-acetpxybenzoyl)- } \beta \text {-D- } \\
\text { glucopyranuronic acid }\end{array}$ & 355 & Phenolic acid & $0.039 \pm 0.013^{\mathrm{a}}$ & $0.060 \pm 0.055^{\mathrm{a}}$ & $0.030 \pm 0.001^{a}$ \\
\hline 5 & o-coumaroylquinic acid & 337 & Phenolic acid & $0.015 \pm 0.002^{c}$ & $0.007 \pm 0.001^{b}$ & $N D^{a}$ \\
\hline 6 & Coumaric acid & 163 & Phenolic acid & $0.025 \pm 0.002^{b}$ & $N D^{a}$ & $N D^{a}$ \\
\hline 7 & $\beta$-glucogallin & 331 & Phenolic acid & $0.149 \pm 0.046^{c}$ & $N D^{a}$ & $0.019 \pm 0.007^{b}$ \\
\hline 8 & Caffeic acid & 179 & Phenolic acid & $0.024 \pm 0.011^{c}$ & $N D^{a}$ & $0.004 \pm 0.004^{b}$ \\
\hline 9 & 2-O-caffeoyl glucarate & 371 & Phenolic acid & $0.063 \pm 0.012^{b}$ & $N D^{a}$ & $N D^{a}$ \\
\hline 10 & $\begin{array}{l}\text { 2,4-Dihydroxy-6-(3-methylbutoxy)-3-(3- } \\
\text { methylbutyl) benzaldehyde }\end{array}$ & 293 & Phenolic acid & $0.007 \pm 0.001^{b}$ & $N D^{a}$ & $N D^{a}$ \\
\hline 11 & Chlorogenic acid derivatives & 467 & Phenolic acid & $0.047 \pm 0.015^{b}$ & $N D^{a}$ & $N D^{a}$ \\
\hline 12 & Coumaroylquinic acid & 337 & Phenolic acid & $N D^{a}$ & $0.017 \pm 0.006^{b}$ & $0.024 \pm 0.001^{b}$ \\
\hline 13 & Chlorogenic acid & 353 & Phenolic acid & $N D^{a}$ & $0.026 \pm 0.074^{b}$ & $0.203 \pm 0.057^{c}$ \\
\hline 14 & 2,5-dihyroxycinnamic acid & 179 & Phenolic acid & $N D^{a}$ & $0.007 \pm 0.002^{b}$ & $0.005 \pm 0.001^{b}$ \\
\hline 15 & $\begin{array}{l}\text { 1-O-(3,4,5-Trihydroxybenzoyl)hexopyra- } \\
\text { nose }\end{array}$ & 331 & Phenolic acid & $N D^{a}$ & $0.005 \pm 0.009^{b}$ & $0.229 \pm 0.017^{c}$ \\
\hline 16 & 4-O-beta-D-glucosyl-4-coumaric acid & 325 & Phenolic acid & $N D^{a}$ & $0.007 \pm 0.007^{b}$ & $N D^{a}$ \\
\hline 17 & Rutin & 609 & Flavonoid & $0.039 \pm 0.034^{b}$ & $N D^{a}$ & $0.020 \pm 0.014^{b}$ \\
\hline 18 & Quercetin glucoside & 463 & Flavonoid & $0.017 \pm 0.004^{b}$ & $N D^{a}$ & $0.254 \pm 0.004^{c}$ \\
\hline 19 & Myricetin-rhamnoside & 463 & Flavonoid & $0.150 \pm 0.005^{b}$ & $N D^{a}$ & $N D^{a}$ \\
\hline 20 & Quercetin glucoside derivative & 649 & Flavonoid & $N D^{a}$ & $0.006 \pm 0.010^{b}$ & $0.110 \pm 0.008^{c}$ \\
\hline 21 & Cyanidin malonylglucoside & 535 & Flavonoid & $N D^{a}$ & $N D^{a}$ & $0.013 \pm 0.010^{b}$ \\
\hline 22 & Cyanidin glucoside & 447 & Flavonoid & $N D^{a}$ & $N D^{a}$ & $0.005 \pm 0.001^{b}$ \\
\hline 23 & Kaempferol hexoside & 447 & Flavonoid & $N D^{a}$ & $N D^{a}$ & $0.061 \pm 0.004^{b}$ \\
\hline 24 & $\begin{array}{l}\text { 6-Metoxykaempferol-3-O-hexose- } \\
\text { O-pentose }\end{array}$ & 577 & Flavonoid & $0.046 \pm 0.055^{b}$ & $N D^{a}$ & $N D^{a}$ \\
\hline 25 & Apigenin pentose & 401 & Flavonoid & $N D^{a}$ & $N D^{a}$ & $0.011 \pm 0.009^{b}$ \\
\hline 26 & Apigenin & 269 & Flavonoid & $N D^{a}$ & $N D^{a}$ & $0.002 \pm 0.000^{b}$ \\
\hline 27 & Naringin & 579 & Flavonoid & $N D^{a}$ & $N D^{a}$ & $0.039 \pm 0.006^{b}$ \\
\hline 28 & Catechin & 289 & Flavonoid & $0.004 \pm 0.000^{b}$ & $N D^{a}$ & $0.018 \pm 0.003^{c}$ \\
\hline 29 & Catechin derivatives & 279 & Flavonoid & $N D^{a}$ & $0.003 \pm 0.005$ & $0.013 \pm 0.004$ \\
\hline 30 & Pelargonidin glucoside & 431 & Anthocyanin & $N D^{a}$ & $N D^{a}$ & $0.002 \pm 0.001^{b}$ \\
\hline 31 & Gallic acid & 169 & $\begin{array}{l}\text { Catabolites/metabolites of } \\
\text { hydrosable tannin }\end{array}$ & $N D^{a}$ & $0.016 \pm 0.016^{b}$ & $0.030 \pm 0.003^{b}$ \\
\hline 32 & Gallic acid derivative & 521 & $\begin{array}{l}\text { Catabolites/metabolites of } \\
\text { hydrosable tannin }\end{array}$ & $0.034 \pm 0.007^{b}$ & $N D^{a}$ & $N D^{a}$ \\
\hline 33 & Gallic acid derivative & $537 /$ & $\begin{array}{l}\text { Catabolites/metabolites of } \\
\text { hydrosable tannin }\end{array}$ & $N D^{a}$ & $0.040 \pm 0.011^{b}$ & $0.761 \pm 0.045^{c}$ \\
\hline 34 & Ellagic acid & 301 & $\begin{array}{l}\text { Catabolites/metabolites of } \\
\text { hydrosable tannin }\end{array}$ & $N D^{a}$ & $0.008 \pm 0.014^{b}$ & $0.124 \pm 0.086^{c}$ \\
\hline 35 & Ellagic acid glucoside & 463 & $\begin{array}{l}\text { Catabolites/metabolites of } \\
\text { hydrosable tannin }\end{array}$ & $0.021 \pm 0.009^{b}$ & $N D^{a}$ & $0.035 \pm 0.032^{b}$ \\
\hline 36 & Ellagic acid methyl pentoside & 447 & $\begin{array}{l}\text { Catabolites/metabolites of } \\
\text { hydrosable tannin }\end{array}$ & $N D^{a}$ & $N D^{a}$ & $0.025 \pm 0.001^{b}$ \\
\hline 37 & Methyl ellagic acid hexose & 477 & $\begin{array}{l}\text { Catabolites/metabolites of } \\
\text { hydrosable tannin }\end{array}$ & $N D^{a}$ & $N D^{a}$ & $0.185 \pm 0.156^{b}$ \\
\hline 38 & Brevifolin & 247 & $\begin{array}{l}\text { Catabolites/metabolites of } \\
\text { hydrosable tannin }\end{array}$ & $0.013 \pm 0.003^{b}$ & $N D^{a}$ & $0.010 \pm 0.006^{b}$ \\
\hline
\end{tabular}


Table 1 (continued)

\begin{tabular}{|c|c|c|c|c|c|c|}
\hline \multirow[t]{2}{*}{ No } & \multirow[t]{2}{*}{ Compound identity } & \multirow[t]{2}{*}{$\mathrm{m} / \mathbf{z}$} & \multirow[t]{2}{*}{ Compound classification } & \multicolumn{3}{|c|}{ Average relative quantification (\%) } \\
\hline & & & & PHWE & $\begin{array}{l}\text { Water (room } \\
\text { temperature) }\end{array}$ & Methanol extract \\
\hline 39 & Brevifolin carboxylic acid & 291 & $\begin{array}{l}\text { Catabolites/metabolites of } \\
\text { hydrosable tannin }\end{array}$ & $0.125 \pm 0.021^{c}$ & $N D^{a}$ & $0.011 \pm 0.001^{b}$ \\
\hline 40 & Brevifolin conjugate & & $\begin{array}{l}\text { Catabolites/metabolites of } \\
\text { hydrosable tannin }\end{array}$ & $0.384 \pm 0.029^{b}$ & $N D^{a}$ & $N D^{a}$ \\
\hline 41 & $\mathrm{~m} / \mathrm{z} 226$ & 226 & $\begin{array}{l}\text { Catabolites/metabolites of } \\
\text { hydrosable tannin }\end{array}$ & $2.117 \pm 3.667^{b}$ & $N D^{a}$ & $N D^{a}$ \\
\hline 42 & m/z 227 & 227 & $\begin{array}{l}\text { Catabolites/metabolites of } \\
\text { hydrosable tannin }\end{array}$ & $4.679 \pm 0.546^{b}$ & $N D^{a}$ & $N D^{a}$ \\
\hline 43 & Geraniin & 951 & Hydrosable tannin & $N D^{a}$ & $N D^{a}$ & $2.380 \pm 0.035^{b}$ \\
\hline 44 & Ellagitannin & 969 & Hydrosable tannin & $0.054 \pm 0.013^{b}$ & $N D^{a}$ & $N D^{a}$ \\
\hline 45 & Dehydrohexahydroxy diphenic acid & 353 & Hydrosable tannin & $0.067 \pm 0.027^{b}$ & $N D^{a}$ & $N D^{a}$ \\
\hline 46 & HHDP-galloyl-glucose & 633 & Hydrosable tannin & $0.407 \pm 0.407^{b}$ & $N D^{a}$ & $N D^{a}$ \\
\hline 47 & HHDP glucose & 783 & Hydrosable tannin & $N D^{a}$ & $N D^{a}$ & $0.008 \pm 0.002^{b}$ \\
\hline 48 & Corilagin & 633 & Hydrosable tannin & $N D^{a}$ & $N D^{a}$ & $0.555 \pm 0.042^{b}$ \\
\hline 49 & Strictinin & 633 & Hydrosable tannin & $N D^{a}$ & $N D^{a}$ & $0.305 \pm 0.147^{b}$ \\
\hline 50 & Castalin & 631 & Hydrosable tannin & $N D^{a}$ & $N D^{a}$ & $0.186 \pm 0.261^{b}$ \\
\hline 51 & Castalagin & 933 & Hydrosable tannin & $N D^{a}$ & $N D^{a}$ & $0.458 \pm 0.050^{b}$ \\
\hline 52 & Proanthocyanidin C1 & 866 & Condensed tannin & $N D^{a}$ & $N D^{a}$ & $0.005 \pm 0.000^{b}$ \\
\hline 53 & Proanthocyanidin trimer & 885 & Condensed tannin & $N D^{a}$ & $N D^{a}$ & $0.002 \pm 0.002^{b}$ \\
\hline
\end{tabular}

Triplicates of results were analyzed by one-way ANOVA with Tukey post hoc and presented as SEM. Different letters indicate significant differences between extract $(\mathrm{p}<0.05)$

ND None detected

fragment ions at $\mathrm{m} / \mathrm{z} 249,193$ and 136. 1-O-(3,4,5-Trihydroxybenzoyl) hexopyranose was found in water (room temperature) and methanol extract only with $\mathrm{m} / \mathrm{z} 331$ and fragment ion MS/MS of m/z 168, 149 and 125.

\section{Flavonoid}

Rutin with $[\mathrm{M}-\mathrm{H}]^{-}$ion at $\mathrm{m} / \mathrm{z}$ of 609 and characteristics fragments of $\mathrm{m} / \mathrm{z}$ with of 301,300 , was identified in PHWE and methanol extract. It is group under flavonoid, made of flavonol quercetin and the disaccharide rutinose. Rutin, also known as vitamin $\mathrm{P}$ is an important health benefiting phytochemical and it has been explored for a number of pharmacological effects including possessing cytoprotective, vasoprotective, anticarcinogenic, neuroprotective and cardioprotective activities [18]. Rutin was also identified in P. niruri [19].

Quercetin glucoside with $[\mathrm{M}-\mathrm{H}]^{-}$ion at $\mathrm{m} / \mathrm{z} 463$ and fragmentation ions MS/MS of $\mathrm{m} / \mathrm{z} 316,271$, and 178, was identified in PHWE and methanol extract. Quercetin has many varied health benefits as documented in the review by Kumar et al. [20].

Myricetin-rhamnoside was identified only in PHWE extract with $\mathrm{m} / \mathrm{z} 463$ and fragmentation ions MS/MS of $\mathrm{m} / \mathrm{z} 316,271$ and 287. Catechin with $[\mathrm{M}-\mathrm{H}]^{-}$ion at $\mathrm{m} / \mathrm{z}$
289 and fragmentation ions MS/MS of 109, 121, 125 and 151 was detected in the PHWE and methanol extract.

Kaempferol hexoside with $[\mathrm{M}-\mathrm{H}]^{-}$ion at $\mathrm{m} / \mathrm{z} 447$ and fragmentation ions MS/MS of 300, 284 and 255 was identified in methanol extract while 6-metoxykaempferol-3-O-hexose- $O$-pentose with $[\mathrm{M}-\mathrm{H}]^{-}$ion at $\mathrm{m} / \mathrm{z}$ 577 and fragmentation ions MS/MS of 243, 225 and 125 was discovered only in PHWE.

Other flavonoids such as apigenin, apigenin pentose, naringin cyanidin glucoside, cyanidin malonylglucoside and the anthocyanin pelargonidin glucoside was only detected in the methanol extract.

\section{Hydrosable tannin}

Geraniin is the highest constituent detected and can only be found in the methanol extract. This is in line with the previous studies that revealed geraniin is the most prevalent component in the methanol extract [21]. It has the configuration $\mathrm{m} / \mathrm{z}$ of 951 and fragment ions of 933, 613 and 301.

Hexahydroxydiphenoyl (HHDP)-galloyl-glucose exhibited a $[\mathrm{M}-\mathrm{H}]^{-}$ion at $\mathrm{m} / \mathrm{z}$ 633, and MS/MS fragment ions at $\mathrm{m} / \mathrm{z} 463$ [M-H-170] $]^{-}$(loss of gallic acid), $\mathrm{m} / \mathrm{z} 301$ $[\mathrm{M}-\mathrm{H}-332]^{-}$(loss of galloyl-glucose) and $\mathrm{m} / \mathrm{z} 275$. This 
compound was only detected in PHWE. HHDP-glucose on the other hand was found only in methanol extract with $[\mathrm{M}-\mathrm{H}]^{-}$ion at $\mathrm{m} / \mathrm{z} 783$ and fragmentation ions MS/MS of 615 [M-H-168 $]^{-}$(loss of galloyl acid), 597 and 301 [M-H-482 $]^{-}$(loss of HHDP-glucose).

Corilagin was only identified in methanol extract with same $[\mathrm{M}-\mathrm{H}]^{-}$ion as HHDP-galloyl-glucose at $\mathrm{m} / \mathrm{z} 633$, and MS/MS fragment ions at $\mathrm{m} / \mathrm{z} 301,275$ and 249 $[\mathrm{M}-\mathrm{H}-146]^{-}$. Corilagin is the isomer of HHDP-galloylglucose [22]. It exhibits activity in lowering the blood pressure through reduction of noradrenaline release. Other than that, previous analysis showed that this compound contains antifungal properties against Candida glabrata [23]. The fragmentations of this compound were also comparable with fragmentation in in Phyllanthus acuminatus [24].

\section{Catabolities/metabolites of hydrosable tannins}

he hydrosable tannnins have a polyhdric alcohol at their core, the hydroxyl groups of which are partially, or fully, esterified with either gallic acid (in gallotannins) or ellagic acids (ellagitannins). Therefore, upon hydrolysis, they release gallic acid, ellagic acid and their derivatives.

Gallic acid was identified in all extracts. Formation of gallic acid with $\mathrm{m} / \mathrm{z} 169$ [M-H-162] $]^{-}$occurred from loss of glucoside and m/z 125 [M-H-44] ${ }^{-}$(loss of $\mathrm{CO}_{2}$ ), m/z $124[\mathrm{M}-\mathrm{H}-45]^{-}$(loss of carboxyl ion $(-\mathrm{COOH})$ through decarboxylation) and $\mathrm{m} / \mathrm{z} 79[\mathrm{M}-\mathrm{H}-90]^{-}$. This data is in line with the spectrum of gallic acid in Nymphaea alba L. and Caesalpinia ferrea $[25,26]$. The highest relative quantity was observed from the PHWE followed by methanol and water (room temperature) extraction suggesting the superiority of PHWE method in extracting valuable bioactive compounds. Gallic acid has recently proved to exhibit strong anti-viral properties [27].

Brevifolin was identified in PHWE extract and methanol with $[\mathrm{M}-\mathrm{H}]^{-}$ion at $\mathrm{m} / \mathrm{z} 247$ and the MS/
MS fragment ions at $\mathrm{m} / \mathrm{z} 135,155$ and 207. Brevifolin carboxylic acid was identified with $[\mathrm{M}-\mathrm{H}]^{-}$ion at $\mathrm{m} / \mathrm{z} 291$, and MS/MS fragment ions at $\mathrm{m} / \mathrm{z} 247$ [M-H$44]^{-}$(loss of carbon dioxide), $\mathrm{m} / \mathrm{z} 191$ (galloyl moiety) $[\mathrm{M}-\mathrm{H}-151]^{-}$(loss of galloyl group) and $\mathrm{m} / \mathrm{z} 145$ $[\mathrm{M}-\mathrm{H}-146]^{-}$(loss of coumarin). Brevifolin carboxylic acid has previously proved to exhibit strong cytotoxic activity towards cancer cells [28] and as a potent antiviral herbal drug [29].

Ellagic acid is a dimeric derivative of gallic acid and can be produced from the hydrolysis of ellagitannins. Ellagic acid was predominantly found in methanol extract with $(\mathrm{M}-\mathrm{H}]^{-}$at $\mathrm{m} / \mathrm{z} 301$ and characteristics fragments MS/MS of $\mathrm{m} / \mathrm{z} 283, \mathrm{~m} / \mathrm{z} 229\left[\mathrm{M}-\mathrm{H}-\mathrm{CO}_{2}-\right.$ $\mathrm{CO}]^{-}$and $\mathrm{m} / \mathrm{z} 185\left[\mathrm{M}-\mathrm{H}-2 \mathrm{CO}_{2}-\mathrm{CO}\right]^{-}$. This finding is in line with the findings of Omar Bakr et al. [25], Zhu et al. [30] and Wyrepkowski et al. [26] where ellagic acid was detected Duchesnea indica and Nymphaea alba. It possesses antioxidant, antiviral, anticancer, antifibrotic and antimutagenic properties [31]. It can also act a drug-metabolizing enzyme that prevents the formation of toxic metabolite [32]. The more polar ellagic acid glucoside with $[\mathrm{M}-\mathrm{H}]^{-}$at $\mathrm{m} / \mathrm{z} 301$ was found in PHWE and methanol extract. Ellagic acid methyl pentoside with $[\mathrm{M}-\mathrm{H}]^{-}$at $\mathrm{m} / \mathrm{z} 447$ and fragmentation ions of 331, 271 and 211 Methyl ellagic acid hexose with $[\mathrm{M}-\mathrm{H}]^{-}$at $\mathrm{m} / \mathrm{z} 477$ and fragmentation ions of 189,169 and 137 was only found in methanol extract.

Unidentified compounds with $\mathrm{mz} 226$ and $\mathrm{mz} 227$ was detected in abundant quantities in PHWE. It has fragmentations patterns of $[\mathrm{M}-\mathrm{H}]^{-}$at $\mathrm{m} / \mathrm{z} 183,112$ and 89 . This compound was believed to be a catabolite of ellagitannin/hydrosable tannin known as Urolithin A as indicated in the Fig. 2.

Proanthocyanidin $\mathrm{C} 1$ and proanthocyanidin trimer was only identified in methanol extract. Proanthocyanidin $\mathrm{C} 1$ has configuration $[\mathrm{M}-\mathrm{H}]^{-}$of 866 and MS/ MS fragment ions at m/z 695, 577 and 287. Meanwhile,

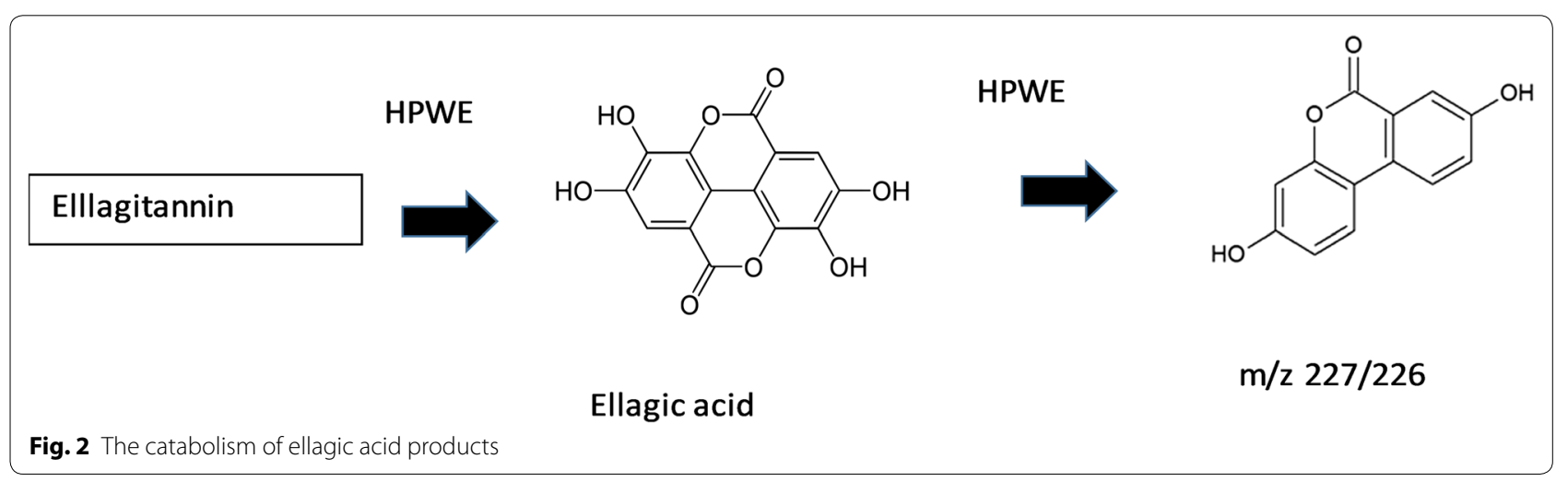


pro-anthocyanidin trimer has $\mathrm{m} / \mathrm{z} 885$, and MS/MS fragment ions at $\mathrm{m} / \mathrm{z} 773$ and 621 .

\section{Overall comparison of extraction between different classes of compounds \\ Phenolic acids}

Caffeoylmalic acid is a hydroxycinnamic acid ester synthesised from caffeic acid and it is moderately nonpolar. It dissolves more readily in methanol compared to water as indicated in Table 1 . This is in line with the findings of Budzianowski [33] and Cho et al. [34]. Other phenolic compounds such as coumaroylquinic acid, and chlorogenic acid are easily subjected to intramolecular isomerisation, transesterification and degradation with high temperature. These compounds degrade to caffeic and quinic acid [35]. This is evident in this finding where at higher temperature and pressure, significantly higher amounts of caffeic acid, quinic acid are present in the PHWE extract and significantly higher amounts of their precursors, coumaroylquinic acid and chlorogenic acid are present in methanol extract (Table 1). Similar trend is seen in the case of 4-O-betaD-glucosyl-4-coumaric acid, where it degrades to coumaric acid and this is evident by the higher amounts of coumaric acid in the PHWE extraction. $\beta$-glucogallin, is formed from gallic acid and $\beta$-D-glucose and is the precursor of ellagic acid. Significantly higher levels of $\beta$-glucogallin in PHWE extract was obtained compared to the other two extraction methods (Table 1). A plausible explanation would be that the conditions of higher temperature and pressure, could have brought about alterations in the existing structure of the molecule in cells, damaging the plant cell wall, thereby reducing the mass transfer resistance and allowing an easier extraction of phytochemicals such as $\beta$-glucogallin and 2-O-caffeoyl glucarate [36].

\section{Flavonoids}

Results from Table 1 and 2 indicate that water at room temperature is a poor solvent for extracting flavonoids from $P$. tenellus unless these compounds are highly polar. The best overall solvent in extracting flavonoids is methanol (Tables 1 and 2). This is in line with the investigations of Dhawan and Gupta [37] and Butsat and Siriamornpun [38]. However, under PHWE conditions, the extraction efficiency of water extraction increase due to its alteration of its self-ionization, dielectric constant, viscosity, diffusivity, density and surface tension as suggested by Khan et al. [36] and Plaza and Turner [39]. With this alteration, water under high temperature and pressure is able to extract significantly higher amounts of flavonoids (42-folds higher) compared to water under room temperature.
Table 2 Comparison of compound groups between extracts

\begin{tabular}{llll}
\hline Compound group & \multicolumn{2}{l}{ Total relative quantification (\%) } \\
\cline { 2 - 4 } & PHWE & $\begin{array}{l}\text { Water (room } \\
\text { temperature) }\end{array}$ & Methanol \\
\hline Phenolic acid & $0.600^{\mathrm{a}}$ & $0.580^{\mathrm{a}}$ & $1.741^{\mathrm{b}}$ \\
Flavonoid & $0.256^{\mathrm{b}}$ & $0.006^{\mathrm{a}}$ & $0.546^{\mathrm{c}}$ \\
Anthocyanin & $0.00^{0 \mathrm{a}}$ & $0.000^{\mathrm{a}}$ & $0.002^{\mathrm{a}}$ \\
Hydrosable tannin and their & $7.933^{\mathrm{c}}$ & $0.008^{\mathrm{a}}$ & $4.282^{\mathrm{b}}$ \\
metabolites/catabolites & & & \\
Condensed tannin & $0.000^{\mathrm{a}}$ & $0.000^{\mathrm{a}}$ & $0.007^{\mathrm{a}}$ \\
\hline
\end{tabular}

Triplicates of results were analyzed by one-way ANOVA with Tukey post hoc and presented as SEM. Different letters indicate significant differences between extract $(p<0.05)$

\section{Hydrosable tannins}

Ellagitannins such as geraniin, strictinin, castalin and castalagin occurs naturally in abundance in Phyllanthus sp. and is most soluble in methanol extract. This is apparent by the results obtained these compounds found in relatively large amounts only in methanol extract and none could be detected in water extractsTable 1). Geraniin, strictinin, castalin and castalagin readily undergo hydrolysis and degradation to its catabolites under heat. Geraninn readily breaks down to brevifolin and its derivatives, corilagin, ellagic acid and gallic acid [40,41]. With higher levels of heat and pressure, we postulate that corilagin, ellagic acid and gallic acid breaks down further to compounds with mz 226 and mz 227 (Fig. 2). These results are reflected in Table 1 and 2 where hydrosable tannin and their metabolites are present higher amounts in PHWE (1.8folds higher) compared to methanol extract. In addition, brevifolin and its derivatives were also found to be present almost 25-folds higher in PHWE compared to methanol extract.

\section{Conclusions}

In this study, the effects of pressurized hot water extraction of the $P$. tenellus on the total extraction and component yields were investigated and compared with that of methanol extract and normal water extract. The results revealed that the solvent/polarity properties of water were significantly enhanced and PHWE managed to extract considerably higher amounts of flavonoids (42-folds higher than water at room temperature) and hydrosable tannins together with their catabolites (991-folds higher than water at room temperature). Higher amounts of hydrolysable tannins and their catabolites were recovered in PHWE than the commonly used methanol extract. This is an important finding as 
pharmacologically active compounds such as brevifolin carboxylic acid, brevifolin derivatives, HHDP-galloylglucose were detected in considerably higher amounts compared to normal water extraction and methanol extract. Although the yields of these individual bioactive compounds are improved in PHWE but they are still relatively low in the absolute sense. This however is complemented by the fact that bioactive compounds normally work synergistically together and when combined there are effective even at lower dose. In addition, PHWE does not require any toxic solvents, convenient, safe and environmentally friendly. This is an improvement compared to conventional techniques where large amounts costly solvents are commonly employed. In addition, the step of chopping or macerating leaves together with homogenisation steps are omitted in the PHWE approach, thus saving cost and time when adopted at the industrial scale. Security risks, such as the toxicity of solvents and the presence of solvent residues in the extracts are also omitted when the PHWE approach is adopted. This technique is envisaged to make a substantial difference in adding value to the herbal industry, and will subsequently reduce the cost of the final product.

\begin{abstract}
Abbreviations
ESI: electrospray ionization; HHDP: hexahydroxydiphenoyl; HPLC: high performance liquid chromatography; IDA: ion detector array; MS/MS: tandem mass spectrometry; MARDI: Malaysian Agricultural Research and Development Institute; NI: negative ion; PHWE: pressurized hot water extraction; TIC: total ion count for each compound; TTIC: total of total ion count for the whole compounds identified in each run; UPLC-qTOF-MS: ultra-high performance liquid chromatography-quadrupole time-of-flight mass spectrometry; $\mathrm{W}_{\mathrm{f}}$ : final weight of crude extract (g); $W_{i}$ : initial weight of extract (g).
\end{abstract}

\section{Acknowledgements}

We thank Chandradevan Machap and Muhamad Aizuddin Ahmad for their technical support.

\section{Authors' contributions \\ Conceptualization was done by IBJ; methodology by IBJ, NHMJ and AS; valida- tion by NHMJ, investigation and formal analysis by IBJ, SKY, KCY, NHMJ and AS; writing — original draft preparation, NHMJ and AS; writing — review and edit- ing by IBJ and SKY; supervision and project administration by IBJ. All authors read and approved the final manuscript.}

\section{Funding}

We thank Malaysian Agriculture Research and Development Institute (MARDI) for funding this project under the special program. This research was funded by Malaysian Agriculture Research and Development Institute (MARDI), Grant Number TP-RB-0055 under special project. The funder has no role in the design of the study; collection, analysis, and interpretation of data; and in writing the manuscript.

\section{Availability of data and materials}

The datasets used and/or analysed during the current study are available from the corresponding author on reasonable request.

\section{Competing interests}

The authors declare that they have no competing interests.

\section{Author details}

${ }^{1}$ Metabolomics Laboratory, Biotechnology Centre, Malaysian Agriculture Research and Development Institute (MARDI), Serdang, Selangor, Malaysia. ${ }^{2}$ China-ASEAN College of Marine Sciences, Xiamen University Malaysia, Sepang, Selangor, Malaysia. ${ }^{3}$ Advanced Chemistry Solutions, Damansara Perdana, Petaling Jaya, Selangor, Malaysia.

Received: 19 September 2019 Accepted: 7 December 2019

Published online: 21 December 2019

\section{References}

1. Silva T, Veras Filho J, Lúcia CDAE, Antonia DSI, Albuquerque U, Cavalcante de Araújo E (2012) Acute toxicity study of stone-breaker (Phyllanthus tenellus Roxb.). Rev Cienc Farm 33:205-210

2. Liu J, Lin H, McIntosh H (2001) Genus Phyllanthus for chronic hepatitis B virus infection: a systematic review. J Viral Hepat 8(5):358-366

3. Tan WC, Jaganath IB, Manikam R, Sekaran SD (2013) Evaluation of antiviral activities of four local Malaysian Phyllanthus species against herpes simplex viruses and possible antiviral target. Int J Med Sci 10(13):1817-1829

4. Shakil A, Kumar J, Pandey K, Saxena B (2008) Nematicidal prenylated flavonones from Phyllanthus niruri. Phytochemistry 69:759-764

5. Ndlebe VJ, Crouch NR, Mulholland DA (2008) Triterpenoids from the African tree Phyllanthus polyanthus. Phytochem Lett 1:11-17

6. Markom M, Hasan M, Wan Daud WR, Singh H, Jahim JM (2007) Extraction of hydrosable tannins from Phyllanthus niruri Linn.: effect of solvents and extraction methods. Sep Purif Technol 52(3):487-496

7. Sparr Eskilsson C, Björklund E (2000) Analytical-scale microwave-assisted extraction. J Chromatogr A 902(1):227-250

8. Mushtaq MY, Choi YH, Verpoorte R, Wilson EG (2014) Extraction for metabolomics: access to the metabolome. Phytochem Anal 25(4):291-306

9. Plaza M, Turner C (2015) Pressurized hot water extraction of bioactives. Trends Anal Chem 71(10):1016

10. Chen H, Tabei K, Siegel MM (2001) Biopolymer sequence using a triple quadrupole mass spectrometer in the ESI Nozzle-Skimmer/Precursor Ion MS/MS mode. J Am Soc Mass Spectrom 12:846-852

11. Brunner $G$ (2005) Supercritical fluids: technology and application to food processing. J Food Eng 67:21-33

12. Snyder LR (1974) Classification of the solvent properties of common liquids. J Chromatogr 92(2):223-230

13. Miller DJ, Hawthorne SB (2000) Solubility of liquid organic flavor and fragrance compounds in subcritical (hot/liquid) water from 298 to 473 K.J. J Chem Eng Data 45:315-318

14. Kheirkhah H, Baroutian S, Young QS (2019) Evaluation of bioactive compounds extracted from Hayward kiwifruit pomace by subcritical water extraction. Food Bioprod Process 115:143-153

15. Bajer T, Bajerová P, Kremr D, Eisner A, Ventura K (2015) Central composite design of pressurised hot water extraction process for extracting capsaicinoids from chili peppers. J Food Compos Anal 40:32-38

16. Machado APDF, Pasquel-Reátegui JL, Barbero GF, Martínez J (2015) Pressurized liquid extraction of bioactive compounds from blackberry (Rubus fruticosus L.) residues: a comparison with conventional methods. Food Res Int 77:675-683

17. Kajdzanoska M, Gjamovski V, Stefova M (2010) HPLC-DAD-ESI-MS identification of phenolic compounds in cultivated strawberries from Macedonia. MACED J Chem Chem En 29:181-194

18. Ganeshpurkar A, Saluja AK (2017) The pharmacological potential of rutin. Saudi Pharm J 25(2):149-164

19. Bagalkotkar G, Sagineedu SR, Saad MS, Stanslas J (2006) Phytochemicals from Phyllanthus niruri Linn. and their pharmacological properties: a review. J Pharm Pharmacol 58(12):1559-1570

20. Kumar R, Vijayalakshmi S, Nadanasabapathi S (2017) Health benefits of Quarcetin. Def Life Sci J 2(2):142-151 
21. Lee SH, Tang YQ, Rathkrishnan A, Wang SM, Ong KC, Manikam R, Sekaran SD (2013) Effects of cocktail of four local Malaysian medicinal plants (Phyllanthus spp.) against dengue virus 2. BMC Comp Altern Med 13:192

22. Dincheva I, Badjakov I, Kondakova V, Dobson P, Mcdougall G, Stewart D (2013) Identification of the phenolic components of Bulgarian raspberry cultivars by LC-ESI-MS. Int J Agric Sci 3:127-138

23. Latte KP, Kolodziej H (2000) Antifungal effects of hydrolysable tannins and related compounds on dermatophytes, mould fungi and yeasts. $Z$ Naturforsch 55:467-472

24. Navarro VM, Moreira I, Arnaez E, Quesada S, Azofeifa G, Vargas F, Alvarado D, Chen P (2017) Flavonoids and ellagitannins characterization, antioxidant and cytotoxic activities of Phyllanthus acuminatus. Plants 6(4):62

25. Omar Bakr R, Wasfi R, Swilam S, Ezz Sallam I (2016) Characterization of bioactive constituents of Nymphaea alba rhizomes and evaluation of anti-biofilm as well as antioxidant and cytotoxic properties. J Med Plants Res 10(26):390-401

26. Wyrepkowski CC, Costa DLMG, Sinhorin AP, Vilegas W, Grandis RA, Resende FA, Varanda EA, Dos Santos LC (2014) Characterization and quantification of the compounds of the ethanolic extract from Caesalpinia ferrea stem bark and evaluation of their mutagenic activity. Molecules 19(10):16039-16057

27. Zhang X, Xia Q, Yang G, Zhu D, Shao Y, Zhang J, Cui Y, Wang R, Zhang L (2017) The anti-HIV-1 activity of polyphenols from Phyllanhus urinaria and the pharmacokinetics and tissue distribution of its marker compound, gallic acid. J Tradit Chin Med Sci 4:158-166

28. Lee IR, Yang MY (1994) Phenolic compounds from Duchesnea chrysantha and their cytotoxic activities in human cancer cell. Arch Pharm Res $17: 476-479$

29. Du G, Xiao M, Yu S, Wang M, Xie Y, Sang S (2018) Phyllanthus urinaria: a potential phytopharmacological source of natural medicine. Int J Clin Exp Med 11(7):6509-6520

30. Zhu M, Dong X, Guo M (2015) Phenolic profiling of Duchesnea indica combining macroporous resin chromatography (MRC) with HPLC-ESIMS/MS and ESI-IT-MS. Molecules 20(12):22463-22475

31. Saldanha E, Joseph N, Ravi R, Kumar A, Shetty V, Fayad R, Shrinath Baliga M (2014) Polyphenols in the prevention of acute pancreatitis. Polyphenols Human Health Dis 1:427-433
32. Hayashi PH, Watkins $P$ (2009) Progress in our understanding of severe drug-induced liver injury. Liver Transpl 15:675-676

33. Budzianowski J (1990) Caffeoylmalic and two pyrrole acids from Parietaria officinalis. Phytochemistry 29:3299-3301

34. Cho JY, Lee YG, Lee SH, Kim WS, Park KH, Moon JH (2014) An ether and three ester derivatives of phenylpropanoid from pear (Pyrus pyrifolia Nakai cv. Chuhwangbae) fruit and their radical-scavenging activity. Food Sci. Biotechnol. 23(1):253-259

35. Gil M, Wianowska D (2017) Chlorogenic acids - their properties, occurrence and analysis. Ann UMCS Sect AA (Chemia) LXXII:61-104

36. Khan SA, Aslam R, Makroo HA (2018) High pressure extraction and its application in the extraction of bio-active compounds: a review. J Food Process Eng 42:312896

37. Dhawan D, Gupta J (2017) Comparison of different solvents for phytochemical extraction potential from Datura metel plant leaves. Int J Biol Chem 11(1):17-22

38. Butsat S, Siriamornpun S (2016) Effect of solvent types and extraction times on phenolic and flavonoid contents and antioxidant activity in leaf extracts of Amomum chinense C. Int Food Res J 23(1):180-187

39. Plaza M, Turner C (2015) Pressurized hot water extraction of bioactives. Trends Anal Chem 71:39-54

40. Cheng HS, Ton SH, Abdul Kadir K (2017) Ellagitannin geraniin: a review of the natural sources, biosynthesis, pharmacokinetics and biological effects. Phytochem Rev 16:159

41. Elendran S, Muniyandy S, Lee WW, Palanisamy UD (2019) Permeability of the ellagitannin geraniin and its metabolites in a human colon adenocarcinoma Caco-2 cell culture model. Food Funct 10(2):602-615

\section{Publisher's Note}

Springer Nature remains neutral with regard to jurisdictional claims in published maps and institutional affiliations.
Ready to submit your research? Choose BMC and benefit from:

- fast, convenient online submission

- thorough peer review by experienced researchers in your field

- rapid publication on acceptance

- support for research data, including large and complex data types

- gold Open Access which fosters wider collaboration and increased citations

- maximum visibility for your research: over $100 \mathrm{M}$ website views per year

At BMC, research is always in progress.

Learn more biomedcentral.com/submissions 